\title{
Liquid film properties of gas-liquid flow in large diameter vertical pipes
}

\author{
M. H. S. Zangana ${ }^{1}$ \& B. J. Azzopardi ${ }^{2}$ \\ ${ }^{1}$ Chemical Engineering Department, \\ School of Petroleum and Chemical Engineering, Faculty of Engineering, \\ Koya University, Kurdistan-Iraq \\ ${ }^{2}$ Process and Environmental Engineering Research Division, \\ Faculty of Engineering, University of Nottingham, UK
}

\begin{abstract}
Systematic experiments have been carried over the ranges of $0.02-0.1 \mathrm{~m} / \mathrm{s}$ and $6.2-16.5 \mathrm{~m} / \mathrm{s}$ liquid and gas superficial velocities respectively. In the experiments the total pressure drop, liquid film thickness and wall shear stress in vertical upward pipes of air-water two phase flow are measured simultaneously on the $127 \mathrm{~mm}$ closed loop facility at Nottingham University. For the overall pressure difference over a length of test section a differential pressure cell was employed. Circumferentially averaged and local film thicknesses were obtained using conductance rings and local pin probes respectively in different locations on the test section. Both magnitude and directional wall shear stress also measured employing the hot film based techniques. In addition, the data were supported by some high speed video images through a visualization campaign. The time series of film thickness show that the interface between the gas and the liquid is rough and that this roughness is visibly influenced by variation in liquid and gas velocities. There are consequent effects in wall shear stress and total pressure drop. From the directional wall shear stress data and the high speed videos is noted that no completely unidirectional upward flow has been observed over the conditions studied. This applies at the upper end of the range of gas velocity studied, a rather unexpected. This might be linked to the characteristics of wave on the liquid film.

Keywords: gas-liquid flows, liquid film properties, film thickness, pressure drop, wall shear stress, large diameter pipes.
\end{abstract}




\section{Introduction}

Large diameter pipes are important in oil and gas production. This is particularly so for offshore industries as they have moved into deeper water. Only few works are known with such size of pipes, and different behaviors of the flow are reported from what has been observed in smaller pipes: e.g. Cheng et al. [1] and Ohnuki and Akimoto [2] show that conventional slug flow does not occur clearly in vertical two phase flow for large diameter pipes. There appears to be a direct transition from bubble flow to churn flow. Ombere-Iyari [3] also did not observe the traditional Taylor bubble of slug flow within the range of his work. These were not the only differences in the behavior of gas and liquid flow in large diameter pipes, but also more different characteristics have been reported, e.g., Azzopardi et al. [4], who studied the disturbance waves in annular two phase flow in a vertical large pipe diameter $(125 \mathrm{~mm})$ showing that they are circumferentially localized, in contrast to what Hewitt and Lovegrove [5] found in a small pipe diameter $(32 \mathrm{~mm})$ that the waves are coherent around the pipe circumference.

In most vertical gas-liquid flow regimes, the liquid phase is traveling partly as a film on the pipe wall regardless of its direction, thickness and the roughness of its surface. In annular type flow the thickness of liquid film on the pipe wall is related to both the liquid film flow rate and wall shear stress according to the triangular relationship (Hewitt and Hall-Taylor [6]). For same type of flow a close relationship between the liquid film thickness and wall shear stress were reported by Martin and Whalley [7]. Both shear stress and liquid film thickness are strongly related to the total pressure drop and the latter consists of three components which are frictional, gravitational and acceleration pressure drop (Hewitt and Whalley [8], Brill and Mukherjee [9] and Azzopardi [10]). The frictional term of pressure drop is represented by shear stress. The gravitational term corresponds to the weight of fluid per unit length of channel which is dominated by the liquid holdup; in annular flow, the liquid holdup is dominated by the liquid film. Besides, the acceleration component of total pressure drop is normally negligible in adiabatic flows. Based on what have been mentioned, the total pressure drop in vertical gas-liquid flow is significantly affected by the liquid film properties such as the thickness of the film, the interfacial roughness of the surface of the film and the shear stress on the pipe wall. Therefore the measurements of such parameters can provide very useful information on the liquid film behavior which affects the overall behavior of the flow. In spite of its great importance such measurements in two-phase vertical flow for large diameter pipes have not; to the author's knowledge, have not been performed prior to the present study. This being the case, total pressure drop, liquid film thickness and wall shear stress were measured selectively and simultaneously during this study. The time-averaged and time-varying total pressure drop, liquid film thickness and wall shear stress are presented. Besides, the direction of the flow of waves on the film is extracted from high speed video images and the time-varying data of locally measured liquid film thicknesses. 


\section{Experimental facility}

The experiments have been carried out using the large scale closed loop facility of $127 \mathrm{~mm}$ id and $11 \mathrm{~m}$ tall riser at Chemical and Environmental Engineering department /Nottingham University (Figure 1). Liquid is stored in the main separator and pumped into the riser base. The gas phase is compressed by two liquid ring vacuum pumps operated in parallel and delivered to the riser base. The phases come together in the mixer and from this point the flow develops along the tall riser. The flow is then directed horizontally into the downcomer and back into the separator. Here the gas is separated from the liquid and the fluids are fed to the compressors and pump. The flow of both fluids can be regulated by valves and the flow rates monitored by flow meters. System pressure can be up to $5 \mathrm{barg}$. Gas and liquid superficial velocities of up to $17 \mathrm{~m} / \mathrm{s}$ and $1.5 \mathrm{~m} / \mathrm{s}$, respectively, can be achieved. Temperatures and pressures are measured at various points throughout the experimental facility. The vertical pipe is equipped with a transparent acrylic resin section (Figure 2) wherein the following measurements are located:

\subsection{Pressure drop}

The total pressure drop is being measured by an electronic differential pressure detectors/transmitters namely, Rosemount 1151 smart model with a range of $0-37.4 \mathrm{kPa}$ and a Rosemount 3051 transmitter with a range of 0-6.23 kPa. Two pressure tappings, separated by an axial distance of $1.64 \mathrm{~m}$ across the transparent section, are connected to the differential pressure device via stainless steel tubes. The tubes were filled with water to keep the density constant. This was assured by an efficient purging procedure which eliminated the risk of gas fractions in the pressure lines. The latter procedure was repeated at the start of each set of the experiments.

\subsection{Liquid film thickness}

In the present study, three parallel conductance ring probes and 4 pairs of pins probe in each side of the test section were employed for the measurement of liquid film thickness. Both techniques are non- intrusive, so the flow is not to be disturbed. The conductance ring probes were located at three different heights on the riser from the mixing unit $(62.7,63.8$ and 65.5 pipe diameters respectively). The thickness of the rings is $3 \mathrm{~mm}$ and the distance between the probes is $25 \mathrm{~mm}$, insulated by non-conducting acrylic resin. This is an electrode separation distance to pipe diameter ratio of 0.20 . The probes were calibrated as described by Van der Meulen et al. [11].

The pin probes were used to locally measure the liquid film thickness on the pipe wall and at four different positions around the wall shear stress probe (Figure 3). Each of the pin probes consists of a pair of stainless rod of $1.5 \mathrm{~mm}$ diameter with a spacing distance of $4.5 \mathrm{~mm}$. For the probes to be perfectly flush with the inner diameter of the test section they were machined very carefully taking different hardness of the steel and the Perspex into consideration. All the 
local pin probes were calibrated simultaneously in the same position as they were located in the test section and with the same signal acquisition arrangement as were used during the experiments

\subsection{Wall shear stress}

During the current study data on wall shear stress in large diameter riser has been obtained using directional wall shear stress probe which is manufactured at Nottingham University. The sensor consists of 5 individual probes (Figure 3 ) which are thin films of nickel, $(0.2 \times 3 \mathrm{~mm})$ for probes 1,3 and 5 and $(0.1 \times 3 \mathrm{~mm})$ for probes 2 and 4 deposited onto a thin sheet of Kapton and coated with 1-1.5 $\mu \mathrm{m}$ of polyamide to protect them from any electrolytic attacks. The probe dimensions were chosen to ensure that the thermal boundary layer was smaller than both the momentum boundary laminar sub-layer and the liquid film thickness for the range of the conditions studied in the present work. The shear stress probes (and their associated flush mounted pin conductance probes) were placed at $8.05 \mathrm{~m}$ above the mixer (i.e. between the first and second conductance ring probes). The probe was calibrated in situ following a similar procedure as described by Zangana et al. [12]. During present study special precautions have been taken to overcome the sources of errors e.g. electrolysis, bubble formation on the probe, effect of temperature changes and probe contamination.

\subsection{Visual studies}

In addition to the measurement techniques mentioned above a high speed video camera (Phantom V7, 1000fps) has been used to visualise the complex structure of air-water flow in the riser. The images were taken in the transparent section of the test section between $7.65 \mathrm{~m}$ and $7.85 \mathrm{~m}$ from the mixer. To reduce the pipe optical curvature the test section was enclosed with a cubic and transparent box filled with water (Figure 2). The picture quality was improved by covering the rear of the pipe with a black plastic sheet as a background and a light source was employed for the clarity of the images.

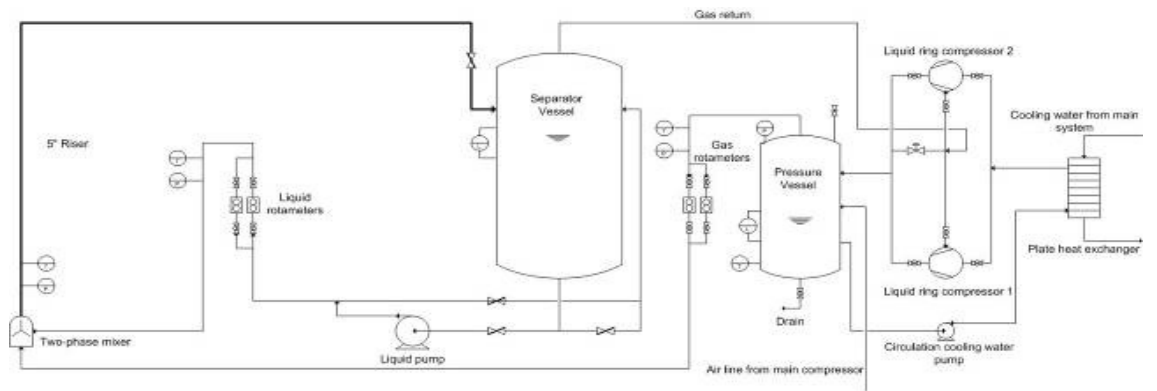

Figure 1: The large scale closed loop test facility at Nottingham University. 


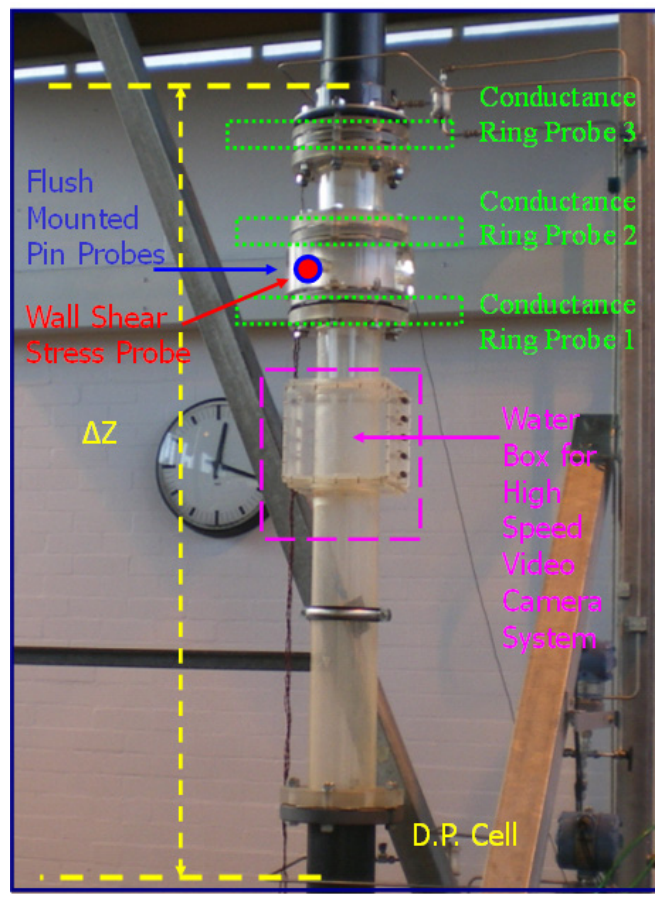

Figure 2: The test section and the location of the measurement techniques.

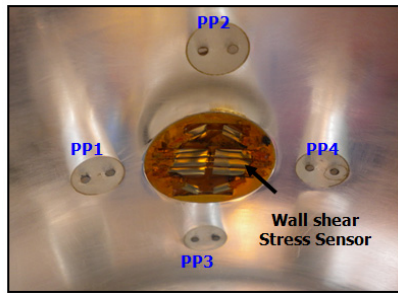

Figure 3: Pin probes and wall shear stress sensor mounted flush inside the test section.

\section{Results and discussion}

With a clear lack of experimental data and information as described previously about liquid film properties in large diameter vertical pipes. In the present study total pressure drop, liquid film thickness and wall shear stress were measured simultaneously in the range of three liquid superficial velocity namely $0.02,0.05$ and $0.1 \mathrm{~m} / \mathrm{s}$ and over different gas velocities. The liquid film properties through the relation between these parameters are investigated and discussed as the following:

\subsection{Time averaged data}

The time-averaged results of measured total pressure drop, liquid film thickness and wall shear stress are illustrated in Figures 4-8 respectively.

\subsubsection{Total pressure drop}

The trend of time averaged total pressure drop as a function of gas superficial velocity for liquid superficial velocities of $0.02,0.05$ and $0.1 \mathrm{~m} / \mathrm{s}$ (Figure 4) can 
be summarised as; at low liquid velocity (i.e., $0.02 \mathrm{~m} / \mathrm{s}$ ) the total pressure rapidly drops as the gas superficial velocity increases to $\approx 10 \mathrm{~m} / \mathrm{s}$ then the change is more gradual at higher gas superficial velocities. It is suggested that the change of the slope linked to a transition of flow regime from churn to annular flow although the lowest pressure drop recorded for this condition was at gas superficial velocity of $15.8 \mathrm{~m} / \mathrm{s}$, however the minimum pressure drop that reported for smaller pipes (Hewitt et al. [13]) is not obvious within the conditions studied. In addition, as we will see from the mean wall shear stress data that zero wall shear stress point is not reached either ([6] and Govan [14]). The variation of total pressure drop with the gas velocity at liquid superficial velocities of 0.05 and $0.1 \mathrm{~m} / \mathrm{s}$ do not follow the trends that seen for the liquid velocity of $0.02 \mathrm{~m} / \mathrm{s}$. At liquid superficial velocity of $0.05 \mathrm{~m} / \mathrm{s}$ the pressure drop has a smoother nature rather than exponential and the trend becomes more complicated as the liquid velocity increases to $0.1 \mathrm{~m} / \mathrm{s}$ where the slope change disappear and become less sensible to the gas velocity variation. However, the overall trend of the variation of total pressure drop with gas velocity is the total pressure drop decreases with the increase of gas velocity over the liquid velocity range studied.

\subsubsection{Liquid film thickness}

The time-averaged liquid film thickness obtained from the conductance ring probes and the liquid film pin probes are presented in Figures 5 and 6 respectively. It is apparent that the variation of liquid film thickness with the gas and liquid superficial velocity has a similar trend as the total pressure drop. The effect of liquid velocity on the film thickness might be explained as; the higher the liquid flow rate the more liquid will be add to the film and the higher the thickness of the film will be. For the effect of gas velocity on the liquid film thickness it is clearly related to the roughness of the interface between the gas and the liquid so as the gas velocity increases it leads to a smoother interface and also to a thinner film. However, when the film is smooth enough, increasing the gas velocity does not lead to a significant decrease in film thickness (e.g. when the gas velocity is greater than $10.1 \mathrm{~m} / \mathrm{s}$ with a liquid velocity of $0.02 \mathrm{~m} / \mathrm{s}$ ). The overall trend of the variation of liquid film thickness with the gas and the liquid

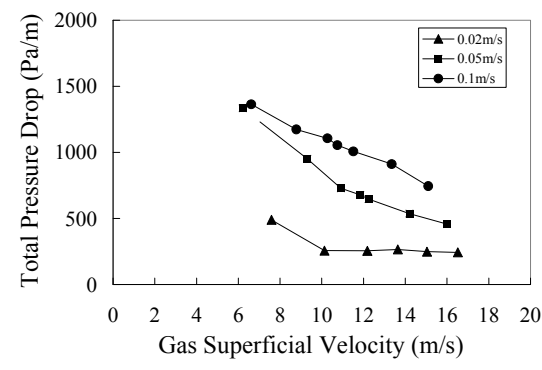

Figure 4: Time-averaged total pressure drop.

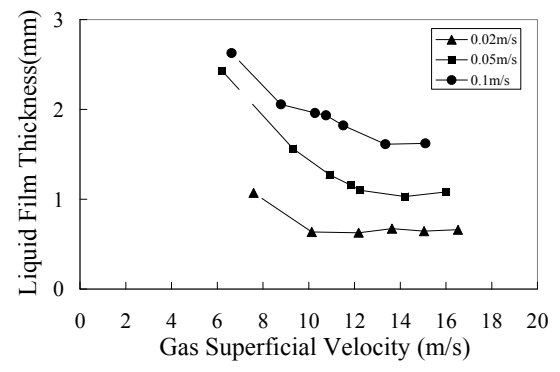

Figure 5: Time-averaged liquid film thickness (ring probes). 


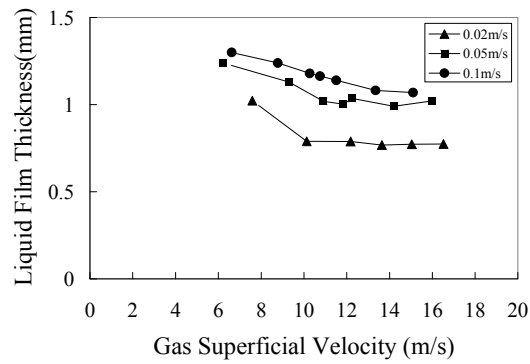

Figure 6: Time-averaged liquid film thickness (pin probes).

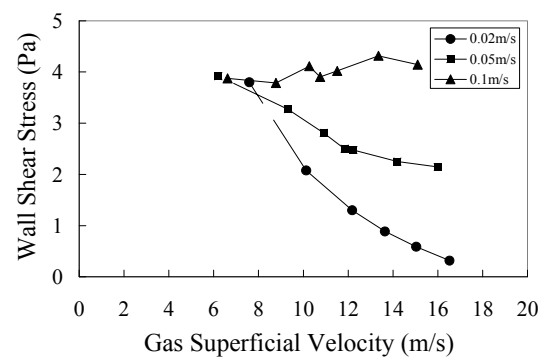

Figure 7: Time-averaged of magnitude wall shear stress.

velocity is the liquid film thickness decreases with increasing gas velocity and decreasing liquid velocity.

\subsubsection{Wall shear stress}

Figures 7 and 8 show the average values of the magnitude and directional wall shear stress respectively. The trends in the values are quite complex; the average of the magnitude of the shear stress also the average of the directional shear stress generally increase with increasing liquid velocity except at low gas velocity. The average magnitude of the shear stress and the average of the directional shear stress generally decrease with increasing gas velocity, though the influence of gas velocity is small at high liquid velocities.

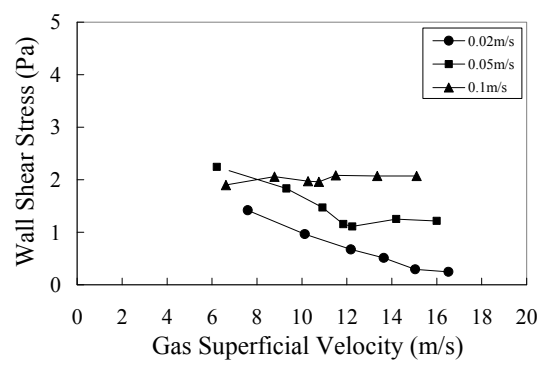

Figure 8: Time-averaged directional wall shear stress.

\subsection{Time-varying data}

Based on the locations of the measurement techniques used in this study on the test section it is believed that the time-varying of total pressure drop that averaged over $1.64 \mathrm{~m}$ axial distance is more reliable to be compared with the time varying data that averaged from the conductance ring probes along the test section. In addition the time-varying wall shear stress results to be compared with the time-varying data from the pin probes. According to the mentioned 
format the time-varying data of the measured parameters are presented in Figure 9 for liquid superficial velocities $\left(\mathrm{U}_{\mathrm{LS}}\right)$ of 0.02 and $0.1 \mathrm{~m} / \mathrm{s}$ and various gas velocities $\left(\mathrm{U}_{\mathrm{GS}}\right)$. It is apparent that there are a noticeable relationship between the total pressure drop and the liquid film thickness that obtained from the conductance ring probes and a close relationship between the time-varying wall shear stress and the liquid film thickness that obtained locally from the pin probes. Due to the averaging nature of the conductance ring probes some details of the roughness in the interface between the gas and the liquid might hide therefore the time-varying film thickness obtained from the pin probes are better related to the wall shear stress results because the later was also measured locally. From the time-varying data of measured parameters it can also be seen that the roughness in the interface between the gas and the liquid are affected by the variation of the liquid and gas velocity. As at liquid velocity of $0.02 \mathrm{~m} / \mathrm{s}$ and gas superficial velocity $16.5 \mathrm{~m} / \mathrm{s}$ only waves with small amplitude or ripples can be seen and a low wall shear stress so consequently a low pressure drop however at liquid velocity of $0.1 \mathrm{~m} / \mathrm{s}$, and gas superficial velocity of $6.6 \mathrm{~m} / \mathrm{s}$ the surface of the film become more rough with higher amplitude waves which leads to a higher wall shear stress and higher pressure drop.
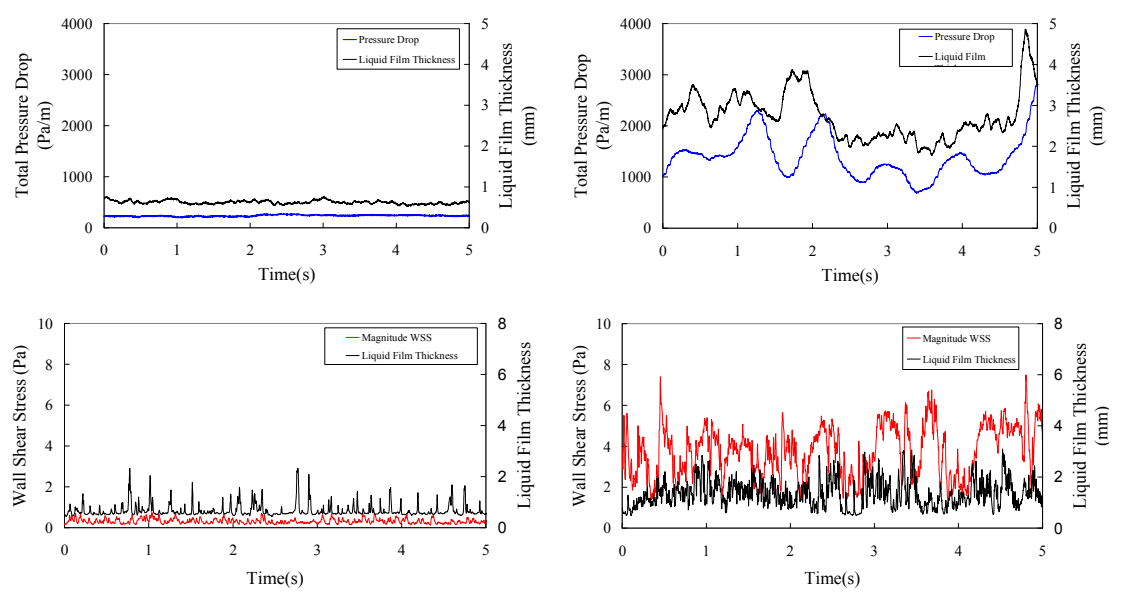

Figure 9: From left to right respectively time-varying data at $\mathrm{U}_{\mathrm{LS}}=0.02 \mathrm{~m} / \mathrm{s}$ and $\mathrm{U}_{\mathrm{GS}}=16.5 \mathrm{~m} / \mathrm{s}$ and $\mathrm{U}_{\mathrm{LS}}=0.1 \mathrm{~m} / \mathrm{s}$ and $\mathrm{U}_{\mathrm{GS}}=6.6 \mathrm{~m} / \mathrm{s}$.

\subsection{The flow direction of the film}

The directional wall shear stress and the local film thickness data were used with some high speed video images to determine the direction of the liquid film flow. A liquid superficial velocity of $0.02 \mathrm{~m} / \mathrm{s}$ was selected at three gas superficial velocities of $16.5,10$ and $7.6 \mathrm{~m} / \mathrm{s}$ which are termed as conditions $\mathrm{A}, \mathrm{B}$ and $\mathrm{C}$ respectively (Figure 10): 


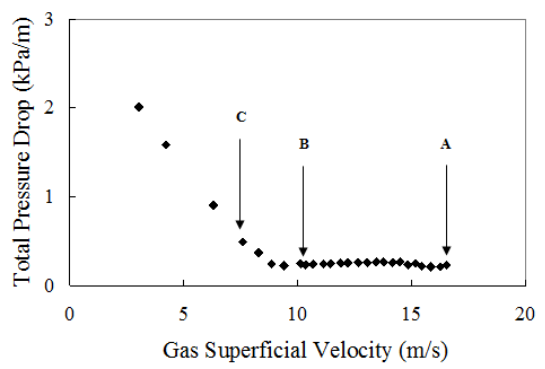

Figure 10: Time-averaged total pressure drop at $\mathrm{U}_{\mathrm{LS}}=0.02 \mathrm{~m} / \mathrm{s}$.

\subsubsection{Directional wall shear stress}

Time-varying results of conditions above from the directional wall shear probe are illustrated in Figure 11. At condition A the wall shear stress is positive for most of the time. However, from time to time it switches to a negative value. As the gas superficial velocities decreases, i.e., at conditions $B$ and $C$, the wall shear stress becomes more random in the fluctuation between negative and positive values. Therefore no completely unidirectional flow was observed over the conditions studied.

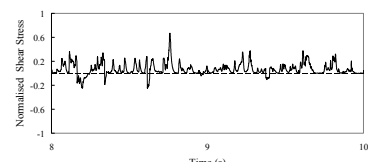

A

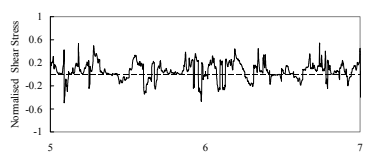

B

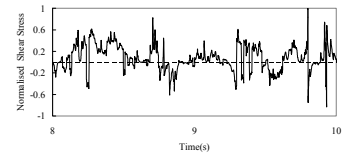

$\mathrm{C}$

Figure 11: Normalized directional wall shear stress for conditions A, B and C.

\subsubsection{Local liquid film thickness}

To investigate the film flow direction the time-varying results of the locally measured film thickness were cross-correlated at Conditions A, B and C. This was carried out between pin probes (PP) 3 and 1, 3 and 2, 3 and 4 (Figure 3), as illustrated in Figure 12 Besides, the structural velocity between each pair of these probes was calculated as shown in Figure 13. The results of Figures 12 and 13 can be summarized as: (i) Overall, positive and negative values in the cross correlation functions can be seen which represent the direction change of the flow over the conditions studied. (ii) According to the location of each probe the cross correlation results and the structural velocity suggest that the film not only moving in the axial direction however two dimensional flows are also might be expected. (iii) Positive and negative values of structural velocities for conditions $\mathrm{A}$ and $\mathrm{C}$ respectively might represent an overall upward flow of the film over 15 sec for the former condition and in contrast to the turbulent complicated churn flow for the later condition. However the structural velocities mostly close to zero for condition B, which means, that the film flow has slowed down. 
A

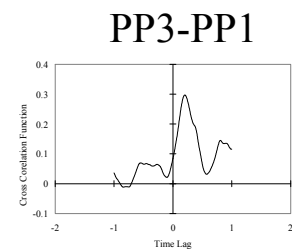

$\mathrm{B}$

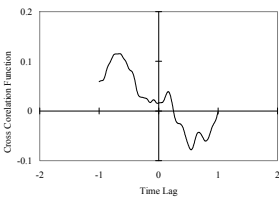

$\mathrm{C}$

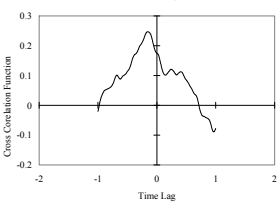

PP3-PP2
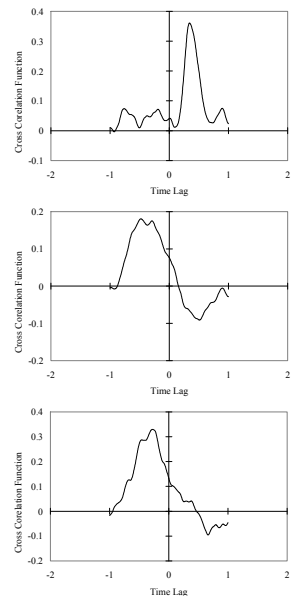

PP3-PP4
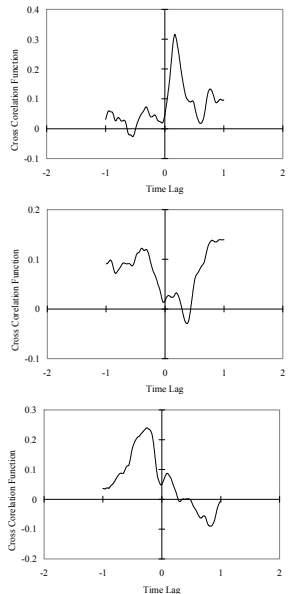

Figure 12: Cross correlation between pin probes for the Conditions A, B and $\mathrm{C}$.
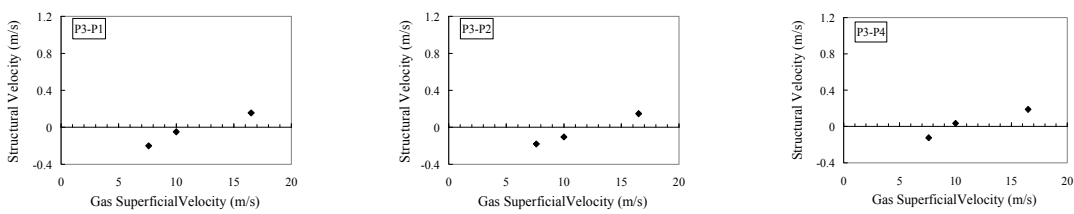

Figure 13: Structural velocities between the local film pin probes.

\subsubsection{High speed video images}

Images extracted from the high speed videos during this study for liquid superficial velocity of $0.014 \mathrm{~m} / \mathrm{s}$ and gas superficial velocities of 16,10 and $3.4 \mathrm{~m} / \mathrm{s}$ are presented in Figure 14. At gas superficial velocity of $16 \mathrm{~m} / \mathrm{s}$ the downward flow of the film is not clear however, the movement of the waves are more clear which are circumferentially localized as reported also by [4]. From the images observed that the waves moving at different velocity and in two dimensional directions, i.e., not only in the axial direction. So when two waves at different velocities moving upward they will collide to produce a bigger wave and as a result: firstly, the liquid film appears to be shock and consequently might move in two dimensional directions for a short period of time. Secondly: due to the gravity that new wave moves downward until becomes small enough to start moving upward again. This might explain the negative values of wall shear stress that observed at condition A. Besides, it may be concluded that in large diameter pipes, waves may move upwards or downwards in contrast to the case for smaller pipes where the film movement is uni-directionally upward. At other two conditions, i.e., at gas superficial velocities of 10 and $3.4 \mathrm{~m} / \mathrm{s}$, the random flow of the film is apparent and becomes more complicated when the gas velocity decreases. 

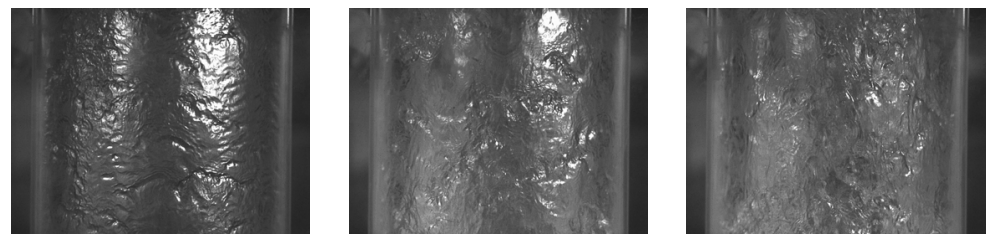

Figure 14: High speed video images for $\mathrm{U}_{\mathrm{LS}}=0.014 \mathrm{~m} / \mathrm{s}$ and $\mathrm{U}_{\mathrm{GS}}=16,10$ and $3.4 \mathrm{~m} / \mathrm{s}$ from left to right respectively.

\section{Conclusions}

The conclusions that may be drawn from the present study are as the following:

1) Over all a noticeable relationship between the parameters measured simultaneously (i.e. Pressure drop, liquid film thickness and wall shear stress) has been observed.

2) The time-varying data of film thickness shown that the roughness in the interface between the gas and the liquid is affected by variation of liquid and gas velocities which consequently effected the time-varying data of both the wall shear stress and the total pressure drop.

3) From the directional wall shear stress probes, no completely unidirectional upward flow has been observed over the conditions studied.

4) The negative values of wall shear stress at gas superficial velocities $>15 \mathrm{~m} / \mathrm{s}$ might be linked to the wave's characteristics on the liquid film according to the high speed videos recorded.

5) On the basis of the information obtained from the local film thickness and the high speed images, two dimensional film flows are expected rather than only an axial flow.

\section{Acknowledgements}

This work has been undertaken within the Joint Project on Transient Multiphase Flows and Flow Assurance. The Authors wish to acknowledge the contributions made to this project by the UK Engineering and Physical Sciences Research Council (EPSRC) and the following: Advantica; BP Exploration; CD-adapco; Chevron; ConocoPhillips; ENI; ExxonMobil; FEESA; IFP; Institutt for Energiteknikk; Norsk Hydro; PDVSA (INTERVEP); Petrobras; PETRONAS; Scandpower PT; Shell; SINTEF; Statoil and TOTAL. The Ministry of Higher Education in the Kurdistan Regional Government and Koya University are highly acknowledged for funding Dr. Zangana's $\mathrm{PhD}$ study at Nottingham University, UK. 


\section{References}

[1] Cheng, H, Hills, J.H. \& Azzopardi, B.J., A study of the bubble to slug transition in vertical gas liquid flow in columns of different diameter. Int. J. Multiphase Flow, Vol. 24, 431-452, 1998.

[2] Ohnuki, A. \& Akimoto, H., Experimental study on transition of flow pattern and phase distribution in upward air wafter two phase flow along a large vertical pipe. Int. J. Multiphase Flow, Vol. 26, 367-386, 2000.

[3] Ombebe-Iyari, N.K., The effect of pipe diameter and pressure in vertical two phase flow, PhD Thesis, University of Nottingham, 2006.

[4] Azzopardi, B.J., Taylor S. \& Gibbons, D.B, Annular two phase flow in a large diameter tube, Int. Conf. Physical Modeling of Multiphase Flow, Coventry, 1983.

[5] Hewitt, G.F. \& Lovegrove, P.C., Frequency and velocity measurements of disturbance waves in annular two-phase flow, UKAEA Report AERE R4304, 1969.

[6] Hewitt, G.F \& Hall-Taylor, N.S Annular two phase flow, pub. Pergamon Press, Oxford, 1970.

[7] Martin, C. J., and Whalley, P. B., Wall Shear Stress Measurement In Annular Two-Phase Flow, BHRA First International Conference on the Physical modeling of multi-phase flow, Coventry, England, Paper G1, 1983.

[8] Hewitt, G. F., and Whalley, P. B, Vertical Annular Two Phase Flow, Multiphase Science and Technology, Vol.4, Chap.2, Hemisphere Publishing, New York, 1989.

[9] Brill, J. P., and Mukherjee, H., Multiphase Flow in Wells, Henry L. Doherty Memorial fund of AIME, Society of petroleum engineers Inc. Richardson, Texas, 1999.

[10] Azzopardi, B.J., Gas-liquid Flows, Pub. Begell House, Inc., 2006.

[11] Van der Meulen, G. P., Zangana, M., Zhao, D. and Azzopardi, B. J., Phase distribution measurements by conductance probes and pressure drop in gas-liquid flows, 7th World Conference on Experimental Heat Transfer, Fluid Mechanics and Thermodynamics, Krakow, Poland on June 28-July 03, 2009.

[12] Zangana, M., Van der Meulen G.P. and Azzopardi B.J, The Effect of Gas and Liquid Velocities on Frictional Pressure Drop in Two Phase Flow for Large Diameter Vertical Pipe, $7^{\text {th }}$ International Conference on Multiphase Flow, ICMF 2010, Tampa, FL, USA, May 30 - June 4, 2010.

[13] Hewitt, G. F., Martin, C.J., and Wilkes, N.S., Experimental And Modeling Studies Of Annular Flow In The Region Between Flow Reversal And The Pressure Drop Minimum, PCH Physico Chemical Hydrodynamics, Vol.6, No.1/2, pp.69-86,1985.

[14] Govan, A. H., Modeling Of Vertical Annular and Dispersed Two-Phase Flows, PhD. Thesis, Imperial College London, UK. 1990. 